\title{
Obstructive Sleep Apnea: Preoperative Screening and Postoperative Care
}

\author{
Robert M. Wolfe, MD, Jonathan Pomerantz, MD, Deborah E. Miller, MD, MACM, \\ Rebecca Weiss-Coleman, MD, and Tony Solomonides, PhD
}

The incidence of obstructive sleep apnea (OSA) has reached epidemic proportions, and it is an often unrecognized cause of perioperative morbidity and mortality. Profound hypoxic injury from apnea during the postoperative period is often misdiagnosed as cardiac arrest due to other causes. Almost a quarter of patients entering a hospital for elective surgery have OSA, and $>80 \%$ of these cases are undiagnosed at the time of surgery. The perioperative period puts patients at high risk of apneic episodes because of drug effects from sedatives, narcotics, and general anesthesia, as well as from the effects of postoperative rapid eye movement sleep changes and postoperative positioning in the hospital bed. For adults, preoperative screening using the STOP or STOP-Bang questionnaires can help to identify adult patients at increased risk of OSA. In the pediatric setting, a question about snoring should be part of every preoperative examination. For patients with known OSA, continuous positive airway pressure should be continued postoperatively. Continuous pulse oximetry monitoring with an alarm system can help to prevent apneic catastrophes caused by OSA in the postoperative period. (J Am Board Fam Med 2016;29:263-275.)

Keywords: Obstructive Sleep Apnea, Opioids, Pediatrics, Respiratory Failure, Respiratory Tract Diseases, Screening, Sleep Disorders, Snoring, Surgery

The Institute of Medicine, in a 2006 publication titled Sleep Disorders and Sleep Deprivation: An Unmet Public Health Problem, noted the widespread underdiagnosis of sleep-related problems by clinicians, and called for increased educational efforts to improve awareness, diagnosis, and treatment. ${ }^{1} \mathrm{Ob}-$ structive sleep apnea (OSA) is a condition in which the upper airway becomes obstructed during sleep,

This article was externally peer reviewed.

Submitted 1 March 2015; revised 16 August 2015; accepted 19 August 2015.

From the Department of Family Medicine, NorthShore University HealthSystem, Evanston, IL (RMW, RW-C); the University of Chicago Pritzker School of Medicine, Chicago, IL (RMW, JP, DEM, RW-C); the Department of Otolaryngology, NorthShore University HealthSystem, Evanston, IL (JP); University of Chicago (NorthShore) Family Medicine Residency, Glenview, IL (DEM); and Clinical Research Informatics, Center for Biomedical Research Informatics; NorthShore University HealthSystem, Evanston, IL (TS).

Funding: none.

Conflict of interest: none declared.

Corresponding author: Robert M. Wolfe, MD, Department of Family Medicine, NorthShore University HealthSystem, 6810 N. McCormick Blvd, Lincolnwood, IL 60712 (E-mail: rwolfe1@uchicago.edu). causing hypoxia, hypercarbia, fragmented sleep, and a variety of medical complications including daytime drowsiness and an increased risk of hypertension, diabetes, and cardiovascular disease. OSA is highly associated with obesity and is becoming increasingly common as the obesity epidemic continues. $^{2}$

The perioperative period is a time of particularly high risk for patients with OSA because of the adverse effects of anesthesia, narcotics, and sedatives on OSA. A number of studies have found that patients with OSA undergoing noncardiac surgery have a higher incidence of postoperative hypoxia, respiratory failure, cardiac events, and intensive care unit (ICU) transfers than those without OSA. ${ }^{3,4}$ Unfortunately, $\geq 80 \%$ of patients with OSA are unrecognized before surgery, putting them at increased risk of complications during the perioperative period. ${ }^{5}$

Family physicians believe OSA is important clinically but often do not address sleep issues. A study of 227 patients and 22 family physicians in 2 family medicine practices found that knowledge of OSA 
among family physicians was high, and $82 \%$ of physicians felt that OSA was very or extremely clinically important. However, physicians documented sleep complaints from patients' review of systems forms only $24 \%$ of the time, and only $11 \%$ of patients with sleep complaints received further workup. The authors noted that "Good physician knowledge and appropriate attitudes about OSA did not translate into high rates of documentation or clinical investigation." "There have been numerous articles on this topic in the surgical and anesthesiology literature, with recent guidelines from the American Society of Anesthesiologists (ASA) and the Society for Ambulatory Anesthesia addressing the issue of perioperative management of patients with OSA. ${ }^{7,8}$ However, a recent search of the family medicine literature revealed only 1 letter to the editor on perioperative aspects of OSA care. ${ }^{9}$

This article addresses the following questions: (1) Should patients contemplating surgery be screened for OSA? (2) Which screening tools are best suited for this purpose? (3) How should patients at risk of OSA or who have OSA be managed in the perioperative and postoperative state?

\section{Methodology}

A keyword search of the Cochrane Library, MEDLINE/PubMed database, and journal archives and current journals from January 1995 through July 2015 was performed using the terms obstructive sleep apnea or sleep apnea in the title or abstract, in combination with the terms screening, surgery, preoperative, postoperative, and perioperative. English-language, peer-reviewed studies assessing the effect of screening for OSA on perioperative morbidity and mortality were reviewed, as were general review articles that included recommendations for management of OSA during the perioperative period. The principal focus was perioperative management of adult OSA, but evidence was also sought for equivalent work on pediatric surgery and management.

\section{Clinical Features}

OSA (sometimes referred to as OSA syndrome [OSAS] when certain symptoms are present - see Table 1) is characterized by partial (hypopnea) or complete closure (apnea) of the upper airway despite ongoing respiratory efforts, leading to oxygen desaturation of the blood, and frequent arousals, resulting in restless sleep (technical terms are defined in Table 1). Adults with OSA typically snore loudly and often report waking from sleep with a choking sensation. The interference with normal sleep leads to daytime drowsiness and many complications in adults, including increased accidents and increased risk of hypertension, diabetes, obesity, stroke, myocardial infarction, and congestive heart failure ${ }^{10,11}$ (Table 2, column 1).

Pediatric OSA presents different symptoms than OSA in adults and is defined differently (Table 1 and Table 2, column 2). The most common cause of OSA in children is adenotonsillar hypertrophy, and adenotonsillectomy is the primary treatment for this condition, curing OSA in 70\% of children. ${ }^{12,13}$ OSA is also associated with obesity and chronic upper airway inflammatory disorders, including sinusitis, allergic rhinitis, and asthma. ${ }^{14}$ Children are less likely to report daytime drowsiness. In children OSA often presents as learning difficulties, behavioral problems, and hyperactivity. ${ }^{15}$ In severe cases hypertension, cardiac dysfunction, and failure to thrive may be seen. ${ }^{16}$ Snoring is a common sign; as many as $40 \%$ of snoring children who are referred for evaluation by an otolaryngologist or sleep specialist prove to have OSA, and the absence of snoring makes a diagnosis of OSA much less likely. ${ }^{12,14,17}$

An illustrative case report exemplifies many of the features of OSA. A woman in her mid-50s was admitted to a hospital for workup of abdominal pain. Several days into her hospital stay she was given parenteral hydromorphone in the evening for pain. Five or 6 hours later she was found by the nurses to be cyanotic and apneic. She was successfully resuscitated and recovered fully after a 2-day ICU stay. She was evaluated by a cardiologist and neurologist. There was no sign of cardiac injury, and cardiac function was normal. She was felt to have had a drug reaction, possibly an interaction between the hydromorphone and a selective serotonin reuptake inhibitor she was taking. A subsequent workup for fatigue included a sleep study that showed mild sleep apnea, which was not treated.

Some months later she was admitted to the same hospital for an endoscopic study, and the evening before the procedure she was premedicated by the gastroenterologist with an intramuscular injection of meperidine. Some time later the nurses 


\begin{tabular}{|c|c|}
\hline Apnea & $\begin{array}{l}\text { Adult: } \geq 90 \% \text { drop in airflow from baseline lasting } \geq 10 \text { seconds* } \\
\text { Children: } \geq 90 \% \text { reduction of airflow from the pre-event baseline for } \geq 2 \text { breaths with } \\
\text { respiratory effort throughout this period }\end{array}$ \\
\hline Hypopnea & $\begin{array}{l}\text { Adult: abnormal respiratory event lasting at least } 10 \text { seconds with } \geq 30 \% \text { reduction in } \\
\text { thoracoabdominal movement or airflow compared with baseline, and with at least a } 4 \% \\
\text { oxygen desaturation }{ }^{18} \\
\text { Children: } \geq 30 \% \text { reduction of nasal airflow from the pre-event baseline for at least } 2 \\
\text { breaths, and with at least a } 3 \% \text { oxygen desaturation }\end{array}$ \\
\hline \multirow[t]{6}{*}{ AHI } & $\begin{array}{l}\text { Number of apneas plus hypopneas per hour of sleep } \\
\text { Based on the AHI, the severity of OSA is classified as follows }{ }^{7,19} \text { : }\end{array}$ \\
\hline & Pediatric criteria (AHI/hour) \\
\hline & None/minimal \\
\hline & Mild \\
\hline & Moderate \\
\hline & Severe \\
\hline Oxygen Desaturation Index & $\begin{array}{l}\text { Hourly average number of desaturation episodes, defined as } \geq 4 \% \text { decrease in saturation } \\
\text { from the average saturation in the preceding } 120 \text { seconds, and lasting }>10 \text { seconds }\end{array}$ \\
\hline Central apnea & Reduction in flow is mainly caused by a reduction in ventilatory effort \\
\hline Obstructive apnea & Reduction in airflow is mainly caused by increased upper airway resistance \\
\hline OSA syndrome & $\begin{array}{l}\text { Adults: AHI score } \geq 15 \text { events/hour or } \geq 5 \text { events/hour with symptoms (such as daytime } \\
\text { somnolence, fatigue, and cognitive impairment; or cardiovascular comorbid conditions, } \\
\text { such as hypertension, ischemic heart disease, or prior stroke) } \\
\text { Children: disorder of breathing during sleep characterized by prolonged partial upper } \\
\text { airway obstruction and/or intermittent complete obstruction (obstructive apnea) that } \\
\text { disrupts normal ventilation during sleep and normal sleep patterns, accompanied by } \\
\text { symptoms or signs } \$\end{array}$ \\
\hline
\end{tabular}

*The American Academy of Sleep Medicine (AASM) definition; Centers for Medicare \& Medicaid Services (CMS) uses cessation of airflow.

${ }^{\dagger}$ Most studies use these criteria. Because of a lack of a uniform definition of obstructive sleep apnea (OSA) severity, the American Society of Anesthesiologists' latest guideline on perioperative management of OSA uses the terms mild, moderate, and severe "as defined by the laboratory where the sleep study was performed." If overall severity is not indicated by the sleep laboratory, they classify OSA severity from Apnea-Hypopnea Index (AHI) as none (0-5), mild (6-20), moderate (21-40), severe $(>40){ }^{7}$

${ }^{\ddagger}$ Criteria for OSA diagnosis of both AASM and the CMS. ${ }^{19}$

Also see Berry et al. ${ }^{20}$

${ }^{\S}$ As listed in Table 2, right column, "Symptoms and Signs of Pediatric OSAS."16

found her cyanotic and apneic, with an agonal heart rhythm. Resuscitation was unsuccessful. The family brought a lawsuit against the gastroenterologist and also against the family physician who had done the preoperative history and physical examination. After expert review determined that the patient had suffered a fatal apneic event caused by the effect of the meperidine injection on her OSA, the family physician was exonerated and dismissed from the case, which was subsequently settled out of court against the gastroenterologist for a substantial sum.

This case study exhibits several of the characteristics of OSA risk, from a near miss, through a failure to follow-up the OSA diagnosis with appropriate treatment or documentation following diagnosis, to a preventable death, and finally to complex litigation. This case parallels the findings of a recent review of medical-legal cases involving patients with OSA in the perioperative setting by
Fouladpour et al, who found that "Slightly over half of the complications reported occurred in an unmonitored setting, and a substantial minority involved the use of opioids. These cases were most likely to be associated with death as the outcome." 21

\section{Pathophysiology}

Breathing is primarily controlled by central respiratory pacemakers in the medulla that interact with central and peripheral chemoreceptors. Central chemoreceptors in the medulla, pons, and cerebellum sense the $\mathrm{pH}$ of the central nervous system, which corresponds to the level (partial pressure) of carbon dioxide in the blood, whereas peripheral chemoreceptors, mainly in the carotid body, are primarily sensitive to changes in the oxygen concentration (partial pressure of arterial oxygen). ${ }^{22}$ The perioperative period is a particularly dangerous time for patients with OSA. General anesthet- 
Table 2. Adult versus Pediatric Obstructive Sleep Apnea

\begin{tabular}{|c|c|}
\hline Clinical Features of Adult OSAS & Symptoms and Signs of Pediatric OSAS \\
\hline Breathing disturbances during sleep & Nocturnal Symptoms \\
\hline Habitual, socially disruptive snoring & Snoring \\
\hline Witnessed apneas & Gasping \\
\hline Gasping or choking & Noisy breathing (typically inspiratory) \\
\hline Difficulties maintaining sleep & Paradoxical breathing \\
\hline Snort arousals & Retractions (cervical or costal) \\
\hline Dyspnea spells & Witnessed apneas \\
\hline Restlessness & Restless sleep \\
\hline Nocturia & Neck hyperextension \\
\hline Diaphoresis & Mouth breathing \\
\hline Gastroesophageal reflux & Nocturnal sweating \\
\hline Daytime dysfunction & Enuresis (after 6 mo continence) \\
\hline $\begin{array}{l}\text { Nonrestorative sleep } \\
\text { Excessive daytime sleepiness in a nonstimulating environment (eg, } \\
\quad \text { watching TV, reading, riding in/driving a car) }\end{array}$ & $\begin{array}{l}\text { Parasomnia (walking, talking, terrors) Bruxism } \\
\text { Mouth breathing } \\
\text { Daytime Symptoms }\end{array}$ \\
\hline Motor vehicle accidents, especially a history of "falling asleep at the wheel" & Difficulty waking Unrefreshed on waking \\
\hline Impaired concentration, cognition, or memory & Excessive sleepiness \\
\hline Headaches upon arising & Hyperactivity \\
\hline Mood lability & Aggression/moodiness \\
\hline Weakened libido & Mouth breathing \\
\hline Risk factors & Poor appetite \\
\hline Obesity & Dysphagia \\
\hline Smoking & Difficulty in school \\
\hline Nasal congestion & Signs/Findings \\
\hline Alcohol & Tonsil hypertrophy \\
\hline Sedative/hypnotics & High/large tongue position \\
\hline Opioid analgesics & Growth disturbance \\
\hline Supine (on the back) sleep positioning & Obesity \\
\hline Comorbidities & Failure to thrive \\
\hline Hypertension & Pulmonary hypertension \\
\hline Myocardial infarction & Systemic hypertension \\
\hline Congestive heart failure & Craniofacial abnormalities \\
\hline Stroke & Laryngomalacia \\
\hline Pulmonary hypertension & Nasal airway obstruction \\
\hline Diabetes/metabolic syndrome & HypotoniaGastroesophageal reflux \\
\hline
\end{tabular}

Column 1 (adult) adapted from Ref. 23. Column 2 (pediatric) reprinted from Ref. 16.

OSAS, obstructive sleep apnea syndrome.

ics, narcotics, and sedatives can worsen airway obstruction by enhancing upper airway muscle relaxation, reducing ventilation, and blunting arousal from sleep. ${ }^{5}$ Narcotics depress both the central response to hypercapnia and the peripheral response to hypoxia: at low doses they primarily decrease tidal volume; at higher doses they decrease the respiratory rate. ${ }^{22}$ Changes in rapid eye movement (REM) sleep during the postoperative period can also put a patient with OSA at risk. Pain and postanesthetic effects can reduce REM sleep, which is followed by a rebound increase in REM sleep 3 to
5 days after surgery. This REM rebound can worsen OSA because REM sleep is normally accompanied by unstable breathing, worsening of airway muscle tone, and a decrease in the arousal response to hypoxia, hypercapnia, and airway occlusion. ${ }^{24-26}$ Adult and pediatric patients with OSA have been found to be highly sensitive to narcotics. ${ }^{27,28}$ One study of children found that those with OSA required approximately half as much morphine for pain relief as children without OSA, likely because of increased sensitivity to opioids caused by recurrent hypoxic episodes. ${ }^{27}$ 
Central sleep apnea is much less common than OSA among postoperative patients. A recent study of 376 postsurgical patients found very low preoperative rates of central sleep apnea, with a significant increase in central apneas on postoperative nights 1 and 3 after general anesthesia in both patients without OSA and those with OSA. However, the clinical significance of this was unclear. $^{29}$

\section{Epidemiology}

The overall prevalence of OSA among the adult population is estimated to be as high as 1 in 4 men and 1 in 10 women, with a higher incidence among surgical patients. ${ }^{30,31}$ In a prospective, observational study, Finkel et $\mathrm{al}^{32}$ screened 2877 adult surgical patients with an OSA risk questionnaire. Of those patients, 661 (24\%) screened as high-risk for OSA, and $81 \%$ of those did not have a diagnosis of OSA. Subsequent sleep studies showed the prevalence of OSA to be $82 \%$ among this high-risk group. The authors estimated the overall prevalence of OSA to be $22 \%$ among the adult surgical population. ${ }^{32}$ Another study found similar rates: of 1506 respondents, $26 \%$ (31\% of men and $21 \%$ of women) met screening questionnaire criteria for high risk of OSA. The risk of OSA was even higher $(57 \%)$ in obese individuals. ${ }^{31}$ The high rates of OSA among surgical patients are likely influenced by the higher prevalence of obesity in studies of these patients. ${ }^{5}$

The rates of diagnosed OSA among adults are lower. Using a nationally representative sample of the US adult population, Li et al estimated that the prevalence of diagnosed sleep apnea was $4.5 \%$ among all adults, $6.1 \%$ among men, and $3.1 \%$ among women. Age-adjusted prevalence was high among people with total obesity (men, $12.1 \%$; women, $7.0 \%$ ) or abdominal obesity (men, $10.9 \%$; women, $4.6 \%){ }^{33}$

Among the pediatric population, OSA affects $1 \%$ to $6 \%$ of all children and up to $59 \%$ of obese children. ${ }^{14}$ Prevalence is higher among males than females, and higher rates have been found among African American children. ${ }^{34}$

\section{Perioperative Risks of OSA}

A number of studies of adult patients with OSA undergoing surgery found a significant increase in postoperative complications, ICU admissions, hos- pital length of stay, dementia, respiratory failure, and episodes of hypoxemia. ${ }^{3,24,35-37}$ Although several large retrospective cohort studies indicated only mild risk ${ }^{38,39}$ or decreased risk of perioperative complications in patients with OSA, ${ }^{40}$ the controls in these studies were patients who were not actually proven to not have OSA, but were simply lacking OSA-related International Classification of Diseases, 9th Revision (ICD-9), diagnosis codes in their charts, thus confounding the result, considering that $>80 \%$ of patients with OSA are undiagnosed. ${ }^{4,32,41}$ A meta-analysis by Kaw et al, comparing patients with OSA with controls who tested negative for OSA or screened at low risk of OSA (and excluding studies using "no ICD-9 codes for OSA" as controls), showed a uniform increase in perioperative morbidity from OSA, with significant heterogeneity of the effect among studies. ${ }^{3}$

Children with OSA are also prone to high rates of complications. One review of 111 cases of death or near-death following tonsillectomy in pediatric patients found that $57 \%$ of the children met criteria for being at risk for OSA. Among this group almost half of the events (46\%) were related to apneas. In 2 of these cases the children were still in the postanesthesia care unit and their monitoring had been discontinued; thought to be asleep, they both died with one of their parents in their room. ${ }^{42}$

Data on mortality rates among adult inpatients are mixed. Although 1 study of patients undergoing arthroplasty revision showed an almost double rate of postoperative mortality among OSA patients compared to patients lacking a diagnosis of OSA, ${ }^{43}$ several other studies showed a lower mortality among OSA patients. ${ }^{38-40}$ In a recent review and meta-analysis, Lyons and Mokhlesi commented extensively on conflicting mortality data. ${ }^{4}$ Regarding the paradoxical finding of decreased mortality among patients with OSA, they note that it may be related to the higher rate of obesity compared with patients without OSA and discuss the "obesity paradox" in which obesity seems to confer protection against mortality for a variety of conditions. ${ }^{44,45}$ They also note that imminent respiratory failure may be recognized and managed earlier in patients with OSA, and that patients without previously diagnosed OSA may nonetheless have OSA and its complications, leading to an underestimation of mortality rates. They conclude by 
Table 3. Screening Techniques for Obstructive Sleep Apnea in Adults

\begin{tabular}{|c|c|c|c|c|c|}
\hline Variables & $\begin{array}{c}\text { Berlin } \\
\text { Questionnaire }\end{array}$ & ASA Checklist & $\begin{array}{c}\text { STOP } \\
\text { Questionnaire }\end{array}$ & $\begin{array}{l}\text { STOP-Bang } \\
\text { Questionnaire }\end{array}$ & $\begin{array}{l}\text { Nocturnal } \\
\text { Oximetry }\end{array}$ \\
\hline Authors & Chung et al. ${ }^{46}$ & Chung et al. ${ }^{46}$ & Chung et al. ${ }^{47}$ & Chung et al. ${ }^{47}$ & Chung et al. ${ }^{48}$ \\
\hline Validation & $\begin{array}{l}\text { Perioperative } \\
\text { setting }\end{array}$ & $\begin{array}{l}\text { Perioperative } \\
\text { setting }\end{array}$ & $\begin{array}{l}\text { Perioperative } \\
\text { setting }\end{array}$ & $\begin{array}{l}\text { Perioperative } \\
\text { setting }\end{array}$ & $\begin{array}{l}\text { Perioperative } \\
\text { setting }\end{array}$ \\
\hline Items (n) & 10 & 14 & 4 & 8 & - \\
\hline High risk of OSA & $\begin{array}{l}\text { Score } \geq 2 \\
\quad \text { categories }\end{array}$ & $\begin{array}{l}\text { Score } \geq 2 \\
\quad \text { categories }\end{array}$ & $\begin{array}{l}\text { Positive score } \\
\quad \geq 2\end{array}$ & $\begin{array}{l}\text { Positive score } \\
\quad \geq 3\end{array}$ & ODI $>10$ \\
\hline \multicolumn{6}{|l|}{$\mathrm{AHI} \geq 15$} \\
\hline Sensitivity (\%) & $78.6(67.1-87.5)$ & $78.6(67.1-87.5)$ & $74.3(62.4-84.0)$ & $92.9(84.1-97.6)$ & $93.3(89.7-97.0)$ \\
\hline Specificity (\%) & $50.5(40.6-62.3)$ & $37.4(28.2-47.3)$ & $53.3(43.4-63.0)$ & $43.0(33.5-52.9)$ & $74.6(69.6-79.6)$ \\
\hline \multicolumn{6}{|l|}{$\mathrm{AHI} \geq 30$} \\
\hline Sensitivity (\%) & $87.2(72.6-95.7)$ & $87.2(72.6-95.7)$ & $79.5(63.5-90.7)$ & $100(91.0-100.0)$ & $100(100-100)$ \\
\hline Specificity (\%) & $46.4(37.9-55.1)$ & $36.2(28.2-44.8)$ & $48.6(40.0-63.0)$ & $37.0(28.9-45.6)$ & $58.6(53.7-63.4)$ \\
\hline
\end{tabular}

Data are presented as mean percentage (95\% confidence interval)

Adapted from Ankichetty and Chung. ${ }^{49}$

AHI, Apnea-Hypopnea Index; ASA, American Society of Anesthesiologists; OSA, obstructive sleep apnea; ODI, Oxygen Desaturation Index (see Table 1 for a definition of ODI).

noting that a number of studies have associated OSA with increased long-term mortality, and because a large number of patients with OSA remain undiagnosed, "the potential for benefit from recognition and referral during preoperative evaluation may be large."

\section{Preoperative Examination and Screening}

During the preoperative history and physical examination, adults should be asked about a prior diagnosis of OSA, snoring, witnessed apneas, daytime drowsiness, and other symptoms associated with OSA (Table 2, column 1). Certain conditions predispose adult patients to a particularly high risk of OSA, including obesity, hypertension, diabetes, male sex, alcohol use, and large neck size $(>43 \mathrm{~cm}$ in males, $>41 \mathrm{~cm}$ in females). Chronic opioid use is also a risk factor for OSA, and chronic users have a higher prevalence of OSA ( $35 \%$ to $39 \%$ ). Opioids cause peripheral chemoreceptors to become less sensitive to hypoxia; this occurs with acute opioid use and does not improve with chronic use. ${ }^{22}$

An ideal screening questionnaire for the primary care setting should be user-friendly, accurate, and generalizable to different target populations. ${ }^{50}$ Four tools validated for screening for OSA in surgical patients are the Berlin questionnaire, the ASA checklist, the STOP questionnaire, and the STOP-Bang questionnaire ${ }^{51}$ (Table 3). Although the STOP questionnaire is the easiest to use, the STOP-Bang modification improves the sensitivity and negative predictive value of the STOP questionnaire and has been shown to be accurate at predicting moderate to severe OSA in surgical patients (sensitivity for detecting OSA at different Apnea-Hypopnea In$\operatorname{dex}[\mathrm{AHI}])$ cutoffs and severity levels: $84 \%$ for $\mathrm{AHI} \geq 5 ; 93 \%$ for $\mathrm{AHI} \geq 15$, and $100 \%$ for $\mathrm{AHI}$ $\geq 30)^{24,50,52-57}$ (Table 4).

Pediatric questionnaires have been developed for the research environment, but a concise questionnaire that is practical in primary care has not yet been fully validated. A 2012 guideline from the American Academy of Pediatrics recommends that all children and adolescents be routinely screened for snoring at routine office visits, and should have a polysomnogram if in addition to snoring there are signs and symptoms of OSA $^{58}$ (Table 2, column 2). A pediatric screening questionnaire called I'M SLEEPY (Table 5) was recently developed and validated in a population of 150 children. ${ }^{59}$ A score $\geq 3$ is sensitive for a diagnosis of OSA. The questionnaire has a sensitivity of $82 \%$, a specificity $50 \%$, and a negative predictive value of $85 \%$ for screening for significant pediatric OSA. Although promising, the initial testing population was small, and further validation is needed to confirm its usefulness as a reliable tool. To date, no pediatric screening questionnaire has been validated with accuracy comparable to that of the STOP-Bang question- 
STOP questionnaire*

1. Snoring? Do you Snore Loudly (loud enough to be heard through closed doors or your bed-partner elbows you for snoring at night)?

2. Tired? Do you often feel Tired, Fatigued, or Sleepy during the daytime (such as falling asleep during driving or talking to someone)?

3. Observed? Has anyone Observed you Stop Breathing or Choking/Gasping during your sleep?

4. Pressure? Do you have or are you being treated for High Blood Pressure?

$\square$ Yes $\square$ No

$\square$ Yes $\square$ No

$\square$ Yes $\square$ No

$\square$ Yes $\square$ No

*High risk of OSA: answering yes to $\geq 2$ questions; Low risk of OSA: answering yes to $<2$ questions.

STOP-Bang questionnaire ${ }^{\dagger}$

1. Snoring? Do you Snore Loudly (loud enough to be heard through closed doors or your bed-partner elbows you for snoring at night)?

2. Tired? Do you often feel Tired, Fatigued, or Sleepy during the daytime (such as falling asleep during $\square$ Yes $\square$ No driving or talking to someone)?

3. Observed? Has anyone Observed you Stop Breathing or Choking/Gasping during your sleep?

4. Pressure? Do you have or are being treated for High Blood Pressure?

5 . Body Mass Index more than $35 \mathrm{~kg} / \mathrm{m}^{2}$ ?

6. Age older than 50 years?

7. Neck size large? (Measured around Adams apple) For male, is your shirt collar 17 inches/43 cm or larger? For female, is your shirt collar 16 inches $/ 41 \mathrm{~cm}$ or larger?

8. Gender: male?

$\square \mathrm{Yes} \square \mathrm{No}$

$\square$ Yes $\square \mathrm{No}$

$\square$ Yes $\square$ No

$\square$ Yes $\square$ No

$\square$ Yes $\square$ No

$\square$ Yes $\square$ No

†For general population:

Low risk of OSA: Yes to 0-2 questions;

Intermediate risk of OSA: Yes to 3-4 questions;

High Risk of OSA: Yes to 5-8 questions

or Yes to 2 or more of 4 STOP questions + male gender

or Yes to 2 or more of 4 STOP questions + BMI $35 \mathrm{~kg} / \mathrm{m} 2$

or Yes to 2 or more of 4 STOP questions + neck circumference $(17$ inches $/ 43 \mathrm{~cm}$ in male, 16 inches/41 cm in female).

Adapted from Refs. 47, 57, and 60 (private communication from Dr. Frances Chung). Stop and STOP-Bang Questionnaires (updated Jan. 2016) courtesy of Dr. Frances Chung, proprietary to University Health Network; http://www.stopbang.ca.

naire for adults, and more research is needed in this area.

\section{Pre- and Postoperative Management}

Family physicians can be an essential part of early recognition of OSA, starting with screening during the preoperative history and physical examination. It is not sufficient to defer assessment solely to the surgical team: a study of 708 surgical patients with no prior diagnosis of OSA found that $38 \%$ had moderate and severe OSA based on preoperative polysomnography ( $\mathrm{AHI} \geq 15$ ); the diagnosis of OSA in this group of patients was missed $60 \%$ of the time by anesthetists and $92 \%$ of the time by surgeons. This study also noted that use of the STOP-Bang questionnaire would have identified $93 \%$ of these patients as being at risk of OSA. ${ }^{41}$

We propose that all adult preoperative patients should, at a minimum, be screened using the STOP or STOP-Bang questionnaire. Primary care physicians screening a pediatric popu- lation should ask about snoring and can use the I'M SLEEPY questionnaire. A screening questionnaire can be made a routine part of standard preoperative examination forms both in paper charts and in electronic health records.

Primary care physicians who identify patients at high risk of OSA based on their history and physical examination and a screening questionnaire should consider referring those patients for a sleep medicine consultation, including a screening home sleep study, or complete polysomnography (time permitting), and appropriate OSA treatment. ${ }^{61}$ Alternatively, patients can be "flagged" as having a high probability for undiagnosed OSA and proceed to surgery if delaying the surgery is deemed unacceptable.

Adult patients deemed as having a high probability of OSA should be managed according to ASA guidelines ${ }^{7}$ (Figure 1). The surgical and anesthesia team need to be notified so perioperative management can be considered, including the use of alternatives to general anesthesia, such 
Table 5. Pediatric Obstructive Sleep Apnea Screening: "I'M SLEEPY" Questionnaire (Parent Version)*

I: Is your child often irritated or angry $\square \mathrm{Yes} \square \mathrm{No}$ during the day?

M: Body mass index $>85 \%$ ?

S: Does your child usually snore?

L: Does your child sometimes have labored breathing at night?

E: Ever noticed a stop in your child's breathing at night?

E: Does your child have enlarged tonsils and/or adenoids?

P: Does your child have problems with concentration?

Y: Does your child often yawn or is he or she often tired/sleepy during the day?

*A score of 0 to 2 indicates a low risk of obstructive sleep apnea (OSA); high risk is indicated by a score $\geq 3$ (sensitivity, $82 \%$; specificity, $50 \%$; negative predictive value, $85 \%$ ). This questionnaire has not yet been validated in larger studies

From Ref. 59.

as regional or peripheral blocks, short-acting opioids, and multimodal analgesia (nonsteroidal anti-inflammatory drugs, acetaminophen, tramadol, ketamine, gabapentin, pregabalin, dexamethasone). ${ }^{62,63}$ Patients designated for sameday discharge should be observed for an extended period (generally up to 3 hours) in the recovery area. ${ }^{64}$ Oxygen desaturation $(<94 \%$, or $\geq 4 \%$ from baseline) during monitoring should be recorded and any apneas documented. If desaturation or apneas are noted and persist within 2 hours of the planned discharge time, then the patient should be admitted to the hospital for overnight observation. In addition, changing a patient's planned discharge from the same day to overnight observation should be considered for patients who require narcotic pain management.

For patients being admitted, pain management restrictions should include patient-controlled anesthesia for narcotic administration, no scheduled intravenous push narcotics, and avoidance of intravenous push hydromorphone (Dilaudid; Perdue Pharma, Stamford, CT). Hydromorphone is highly potent $(1 \mathrm{mg}$ of hydromorphone is equivalent to 8 to $10 \mathrm{mg}$ of morphine), and many physicians underestimate the severity of its respiratory depressant effects. A retrospective analysis of 32 cases of respiratory failure at 1 medical center found that 3 of 4 deaths were associated with hydromorphone as the primary parenteral opioid. ${ }^{28}$ For this reason, morphine sulfate is preferred over hydromorphone for parenteral analgesia. Codeine should be avoided, especially in children, because its CYP2D6 metabolism to the active drug (morphine) is inconsistent, sometimes causing it to be ineffective in poor metabolizers, and occasionally leading to morphine overdose and death in extensive metabolizers. ${ }^{65,66}$

Patients with OSA should have continuous pulse oximetry monitoring with audible alarms for desaturation below $90 \%$ partial pressure of oxygen. Patients should preferably be within the line of sight of the nursing station. ${ }^{67}$ Supplemental oxygen should have a stop order set at 2 $\mathrm{L} / \mathrm{min}$ (ie, the nurse must contact a physician to titrate the oxygen above $2 \mathrm{~L} / \mathrm{min}$ ). This is because the central response to hypoxia is reduced and the hypercapnic response is markedly reduced during REM sleep. Therefore excess oxygen could induce hypoventilation/hypercapnia by suppressing the central hypoxia response and by raising oxygen concentrations; this could delay the recognition of a respiratory problem by pulse oximetry. ${ }^{67}$

If possible, patients should be positioned to sleep on their side, or in a semiupright or other nonsupine position, since the supine position aggravates OSA by increasing the ability of the pharynx to collapse. ${ }^{7,29}$ Continuous positive airway pressure therapy can be administered for patients suspected to have undiagnosed severe OSA. All patients identified as having a high probability for undiagnosed OSA (same-day surgery patients going home and patients discharged from an overnight stay) should receive discharge instructions for follow-up with a sleep medicine consultant and with educational information on OSA, as well as instructions to avoid risks associated with postoperative narcotic use for pain control. (See Figures 1 and 2 for perioperative management algorithms; Table 6 for SOR).

\section{Recommendations}

In our opinion, use of the STOP or STOP-Bang questionnaire should become part of every adult preoperative examination. All pediatric preoperative exams should include a question about snoring; the I'M SLEEPY questionnaire can be used to further screen children at high risk of OSA, although this questionnaire requires further val- 
Figure 1. Perioperative management of adult patients with obstructive sleep apnea (OSA) or at high risk for OSA undergoing elective, non- upper airway surgery. CPAP, continuous positive airway pressure; FRC, functional residual capacity; PAP, positive airway pressure; PSG, polysomnography. Adapted from Adesanya et al. ${ }^{5}$

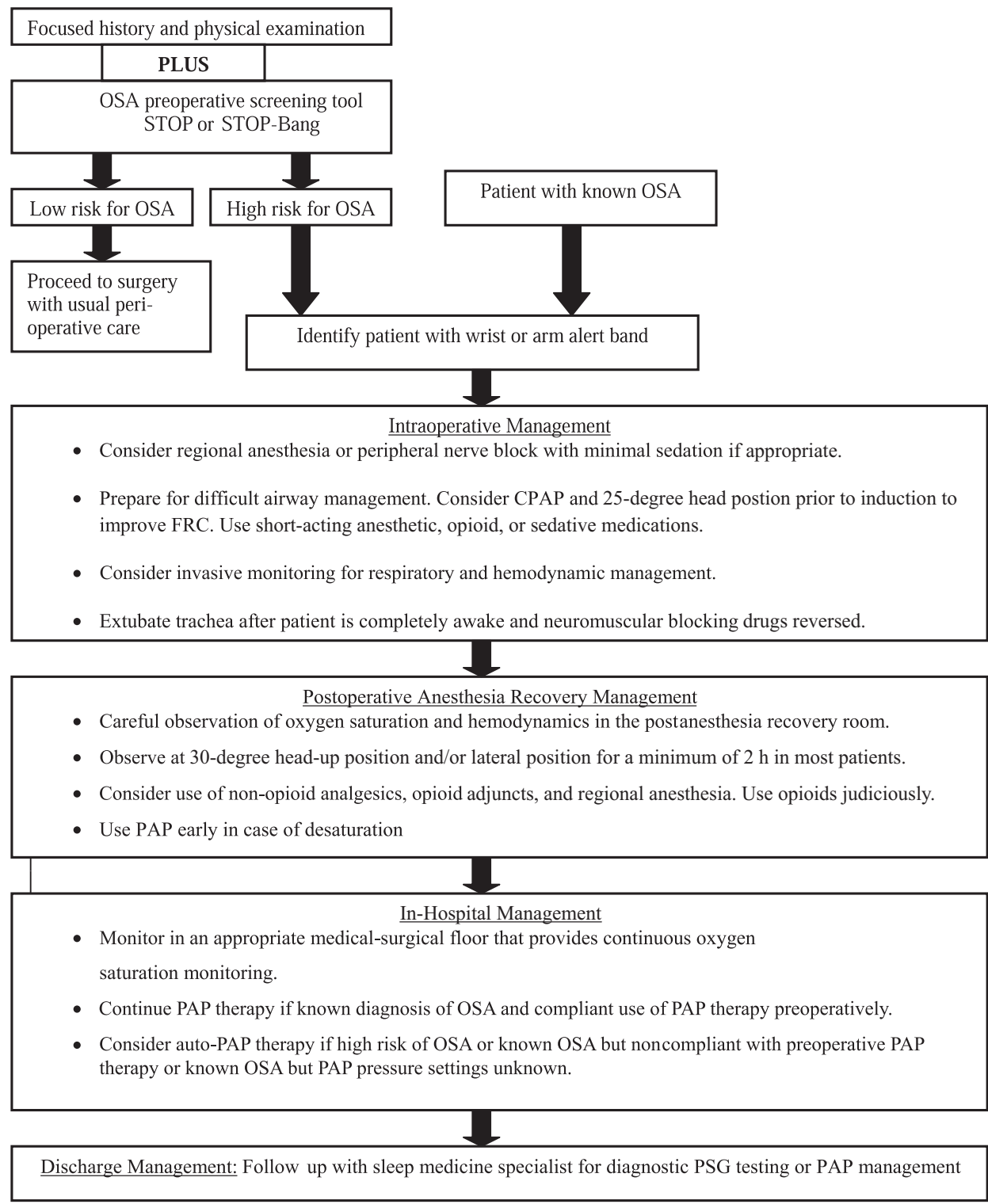

idation. The surgical team should be made aware of patients identified as having a high risk of OSA. When time permits during the period before surgery, high-risk patients should have a consultation with a sleep specialist and a home screening sleep study or complete polysomnography ordered when practical. Family physicians involved with the care of surgical inpatients should be aggressive about checking postoperative orders to ensure that patients at high risk of OSA have, at a minimum, continuous pulse oxi- metry monitoring with an alarm as a precaution against unobserved respiratory failure. Follow-up for OSA treatment after discharge is also essential for patients newly diagnosed through the screening process.

Finally, hospitals need to have standardized practice guidelines or order sets to guide the management of surgical patients with OSA. A U.S. survey (783 responses) found that only $27 \%$ of respondents reported that their institution had a written policy for the perioperative care of patients 
Figure 2. Post-adenotonsillectomy disposition of children with obstructive sleep apnea (OSA). *Comorbidities in children $<3$ years old include severe OSA documented by polysomnography (PSG), failure to thrive, obesity, cardiac involvement (right ventricular hypertrophy), Down syndrome, history of prematurity, craniofacial abnormalities, neuromuscular diseases, chronic lung disease, and sickle cell disease (comorbidities are taken from Table 3 in Ref. ${ }^{65}$ ). AHI, Apnea-Hypopnea Index. From Patino et al. ${ }^{65}$

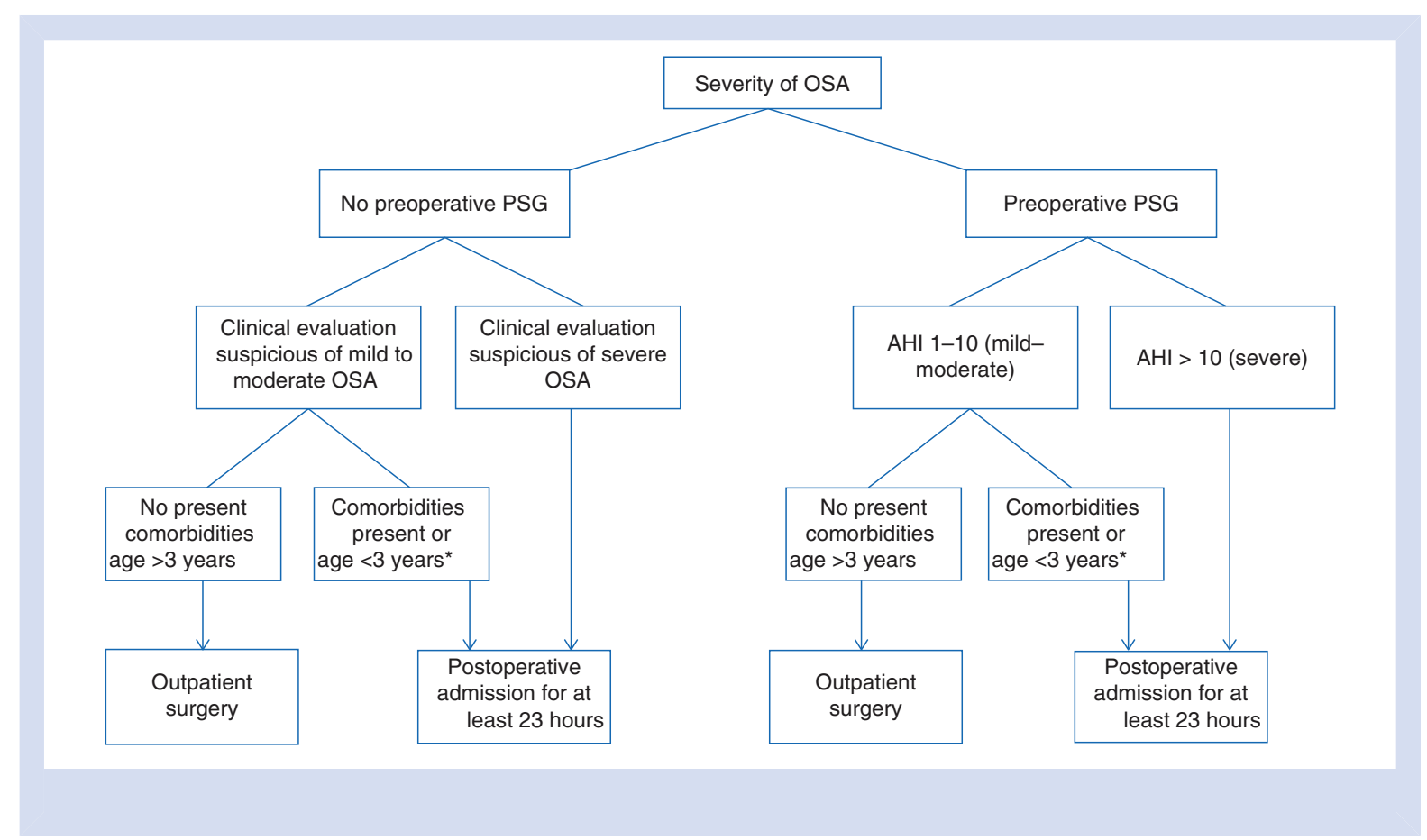

with OSA, with the highest awareness among sleep medicine physicians $35 \%$ reported having such a policy). Only $6 \%$ of internal medicine and family medicine physicians surveyed acknowledged having such a policy. ${ }^{68}$ A Canadian survey (773 responses) found that $53 \%$ of respondents indicated a policy was present in their institution; $34 \%$ of the respondents specified that no policy was present, and 13\% did not know. ${ }^{69}$ Thus it seems likely that almost half of Canadian and perhaps two thirds of American healthcare institutions do not have policies on this topic; certainly family physicians and internists are mostly unaware of these policies if they do exist. Family physicians have an opportunity, through their involvement with their local hospitals and hospital committees, to be leaders in helping to implement policy standards for surgical patients with OSA.

Table 6. Strength of Recommendation Taxonomy

\begin{tabular}{|c|c|c|}
\hline Practice Recommendation & $\begin{array}{l}\text { Level of } \\
\text { Evidence }\end{array}$ & References \\
\hline $\begin{array}{l}\text { A question about snoring should be part of every pediatric preoperative assessment.* If the answer } \\
\text { is affirmative or if a child or adolescent presents with signs or symptoms of OSAS, clinicians } \\
\text { should perform a more focused evaluation. }\end{array}$ & B & 58 \\
\hline $\begin{array}{l}\text { Preoperative screening using the STOP or STOP-Bang questionnaire should become routine to } \\
\text { identify adult patients at increased risk of OSA. }\end{array}$ & $\mathrm{C}$ & 50,70 \\
\hline $\begin{array}{l}\text { Continuous postoperative monitoring with pulse oximetry is effective in detecting hypoxemic } \\
\text { events in patients with known or suspected OSA. }\end{array}$ & B & 7 \\
\hline
\end{tabular}

*The original American Academy of Pediatrics guideline recommends asking about snoring "as part of routine health maintenance visits."

OSA, obstructive sleep apnea; OSAS, obstructive sleep apnea syndrome. 
The authors wish to acknowledge Neil S. Freedman, MD, Department of Pulmonary and Critical Care Medicine, NorthShore University HealthSystem, Evanston, IL, for helpful suggestions regarding postoperative care of the OSA patient.

\section{References}

1. Colten HR, Altevogt BM, eds. Sleep disorders and sleep deprivation: an unmet public health problem. Washington, DC: Committee on Sleep Medicine and Research, Institute of Medicine/National Academies Press; 2006.

2. Peppard PE, Young T, Barnet JH, Palta M, Hagen EW, Hla KM. Increased prevalence of sleep-disordered breathing in adults. Am J Epidemiol 2013;177: 1006-14.

3. Kaw R, Chung F, Pasupuleti V, Mehta J, Gay PC, Hernandez AV. Meta-analysis of the association between obstructive sleep apnoea and postoperative outcome. Br J Anaesth 2012;109:897-906.

4. Lyons P, Mokhlesi B. Diagnosis and management of obstructive sleep apnea in the perioperative setting. Semin Respir Crit Care Med 2014;35:571-81.

5. Adesanya AO, Lee W, Greilich NB, Joshi GP. Perioperative management of obstructive sleep apnea. Chest 2010;138:1489-98.

6. Grover M, Mookadam M, Armas D, et al. Identifying patients at risk for obstructive sleep apnea in a primary care practice. J Am Board Fam Med 2011; 24:152-60.

7. Gross JB, Apfelbaum JL, Caplan RA, et al. Practice guidelines for the perioperative management of patients with obstructive sleep apnea: an updated report by the American Society of Anesthesiologists Task Force on Perioperative Management of Patients with Obstructive Sleep Apnea. Anesthesiology 2014;120:268-86.

8. Joshi GP, Ankichetty SP, Gan TJ, Chung FM. Society for Ambulatory Anesthesia consensus statement on preoperative selection of adult patients with obstructive sleep apnea scheduled for ambulatory surgery. Anesth Analg 2012;115:1060-8.

9. Grigg P, Lickteig C. Perioperative screening for obstructive sleep apnea. Am Fam Physician 2002;66: 958, 963-4.

10. Young T, Peppard PE, Gottlieb DJ. Epidemiology of obstructive sleep apnea. Am J Respir Crit Care Med 2002;165:1217-39.

11. Krieger J, McNicholas WT, Levy P, et al. Public health and medicolegal implications of sleep apnoea. Eur Respir J 2002;20:1594-609.

12. Marcus CL, Brooks LJ, Ward SD, et al. Technical report: diagnosis and management of childhood obstructive sleep apnea syndrome. Pediatrics 2012;130: e714-55.

13. Coté CJ. Anesthesiological considerations for children with obstructive sleep apnea. Curr Opin Anaesthesiol 2015;28:327-32.
14. Schwengel DA, Dalesio NM, Stierer TL. Pediatric obstructive sleep apnea. Anesthesiol Clin 2014;32: 237-61.

15. Verhulst S, Kaditis A. Obstructive sleep apnoea in children. Breathe 2011;7:240-7.

16. Alexander NS, Schroeder JW Jr. Pediatric obstructive sleep apnea syndrome. Pediatr Clin North Am 2013;60:827-40.

17. Carroll JL, McColley SA, Marcus CL, Curtis S, Loughlin GM. Inability of clinical history to distinguish primary snoring from obstructive sleep apnea syndrome in children. Chest 1995;108:610-8.

18. Centers for Medicare \& Medicaid Services. National coverage determination (NCD) for continuous positive airway pressure (CPAP) therapy for obstructive sleep apnea (OSA) (240.4). 2008. Available from: https://www.cms.gov/Medicare/Coverage/Coveragewith-Evidence-Development/Continuous-PositiveAirway-Pressure-CPAP-Therapy-For-ObstructiveSleep-Apnea-OSA-2404.html. Accessed February 9, 2016.

19. Qaseem A, Dallas P, Owens DK, Starkey M, Holty J-EC, Shekelle P. Diagnosis of obstructive sleep apnea in adults: a clinical practice guideline from the American College of Physicians. Ann Intern Med 2014;161:210-20.

20. Berry RB, Budhiraja R, Gottlieb DJ, et al. Rules for scoring respiratory events in sleep: update of the 2007 AASM manual for the scoring of sleep and associated events. J Clin Sleep Med 2012;8:597-619.

21. Fouladpour N, Jesudoss R, Bolden N, Shaman Z, Auckley D. Perioperative complications in obstructive sleep apnea patients undergoing surgery: a review of the legal literature. Anesth Analg 2016;122:145-51.

22. Zutler M, Holty J-EC. Opioids, sleep, and sleepdisordered breathing. Curr Pharm Des 2011;17: 1443-9.

23. Olson EJ, Park JG, Morgenthaler TI. Obstructive sleep apnea-hypopnea syndrome. Prim Care 2005; 32:329-59.

24. Vasu TS, Grewal R, Doghramji K. Obstructive sleep apnea syndrome and perioperative complications: a systematic review of the literature. J Clin Sleep Med 2012;8:199-207.

25. Walker JM, Farney RJ. Are opioids associated with sleep apnea? A review of the evidence. Curr Pain Headache Rep 2009;13:120-6.

26. Yue HJ, Guilleminault C. Opioid medication and sleep-disordered breathing. Med Clin North Am 2010;94:435-46.

27. Brown KA, Laferrière A, Lakheeram I, Moss IR. Recurrent hypoxemia in children is associated with increased analgesic sensitivity to opiates. Anesthesiology 2006;105:665-9.

28. Ramachandran SK, Haider N, Saran KA, et al. Lifethreatening critical respiratory events: a retrospective study of postoperative patients found unrespon- 
sive during analgesic therapy. J Clin Anesth 2011;23: 207-13.

29. Chung F, Liao P, Elsaid H, Shapiro CM, Kang W. Factors associated with postoperative exacerbation of sleep-disordered breathing. Anesthesiology 2014; 120:299-311.

30. Memtsoudis SG, Besculides MC, Mazumdar M. A rude awakening - the perioperative sleep apnea epidemic. N Engl J Med 2013;368:2352-3.

31. Hiestand DM, Britz P, Goldman M, Phillips B. Prevalence of symptoms and risk of sleep apnea in the US population: results from the National Sleep Foundation Sleep in America 2005 poll. Chest 2006; 130:780-6.

32. Finkel KJ, Searleman AC, Tymkew H, et al. Prevalence of undiagnosed obstructive sleep apnea among adult surgical patients in an academic medical center. Sleep Med 2009;10:753-8.

33. Li C, Ford ES, Zhao G, Croft JB, Balluz LS, Mokdad AH. Prevalence of self-reported clinically diagnosed sleep apnea according to obesity status in men and women: National Health and Nutrition Examination Survey, 2005-2006. Prev Med 2010;51:18-23.

34. Lumeng JC, Chervin RD. Epidemiology of pediatric obstructive sleep apnea. Proc Am Thorac Soc 2008;5: 242-52.

35. Memtsoudis S, Liu SS, Ma Y, et al. Perioperative pulmonary outcomes in patients with sleep apnea after noncardiac surgery. Anesth Analg 2011;112: 113-21.

36. Bateman BT, Eikermann M. Obstructive sleep apnea predicts adverse perioperative outcome: evidence for an association between obstructive sleep apnea and delirium. Anesthesiology 2012;116:753-5.

37. Liao P, Yegneswaran B, Vairavanathan S, Zilberman $\mathrm{P}$, Chung F. Postoperative complications in patients with obstructive sleep apnea: a retrospective matched cohort study. Can J Anaesth 2009;56:819-28.

38. Mokhlesi B, Hovda MD, Vekhter B, Arora VM, Chung F, Meltzer DO. Sleep-disordered breathing and postoperative outcomes after elective surgery: analysis of the nationwide inpatient sample. Chest 2013;144:903-14.

39. Mokhlesi B, Hovda MD, Vekhter B, Arora VM, Chung F, Meltzer DO. Sleep-disordered breathing and postoperative outcomes after bariatric surgery: analysis of the Nationwide Inpatient Sample. Obes Surg 2013;23:1842-51.

40. Lyons PG, Zadravecz FJ, Edelson DP, Mokhlesi B, Churpek MM. Obstructive sleep apnea and adverse outcomes in surgical and nonsurgical patients on the wards. J Hosp Med 2015;10:592-8.

41. Singh M, Liao P, Kobah S, Wijeysundera DN, Shapiro C, Chung F. Proportion of surgical patients with undiagnosed obstructive sleep apnoea. Br J Anaesth 2013;110:629-36.

42. Coté CJ, Posner KL, Domino KB. Death or neurologic injury after tonsillectomy in children with a focus on obstructive sleep apnea: Houston, we have a problem! Anesth Analg 2014;118:1276-83.

43. D'Apuzzo MR, Browne JA. Obstructive sleep apnea as a risk factor for postoperative complications after revision joint arthroplasty. J Arthroplasty 2012;27(8 Suppl):95-8.

44. Memtsoudis SG, Bombardieri AM, Ma Y, Walz JM, Chiu YL, Mazumdar M. Mortality of patients with respiratory insufficiency and adult respiratory distress syndrome after surgery: the obesity paradox. J Intensive Care Med 2012;27:306-11.

45. Bucholz EM, Rathore SS, Reid KJ, et al. Body mass index and mortality in acute myocardial infarction patients. Am J Med 2012;125:796-803.

46. Chung F, Yegneswaran B, Liao P, et al. Validation of the Berlin questionnaire and American Society of Anesthesiologists checklist as screening tools for obstructive sleep apnea in surgical patients. Anesthesiology 2008;108:822-30.

47. Chung F, Yegneswaran B, Liao P, et al. STOP questionnaire: a tool to screen patients for obstructive sleep apnea. Anesthesiology 2008;108:812-21.

48. Chung F, Liao P, Elsaid H, Islam S, Shapiro CM, Sun Y. Oxygen desaturation index from nocturnal oximetry: a sensitive and specific tool to detect sleepdisordered breathing in surgical patients. Anesth Analg 2012;114:993-1000.

49. Ankichetty S, Chung F. Considerations for patients with obstructive sleep apnea undergoing ambulatory surgery. Curr Opin Anaesthesiol 2011; 24:605-11.

50. Abrishami A, Khajehdehi A, Chung F. A systematic review of screening questionnaires for obstructive sleep apnea. Can J Anaesth 2010;57:423-38.

51. Shafazand S. Perioperative management of obstructive sleep apnea: ready for prime time? Cleve Clin J Med 2009;76(Suppl 4):S98-103.

52. Chung F, Yang Y, Liao P. Predictive performance of the STOP-Bang score for identifying obstructive sleep apnea in obese patients. Obes Surg 2013;23: 2050-7.

53. Chung F, Subramanyam R, Liao P, Sasaki E, Shapiro C, Sun Y. High STOP-Bang score indicates a high probability of obstructive sleep apnoea. Br J Anaesth 2012;108:768-75.

54. Farney RJ, Walker BS, Farney RM, Snow GL, Walker JM. The STOP-Bang equivalent model and prediction of severity of obstructive sleep apnea: relation to polysomnographic measurements of the apnea/hypopnea index. J Clin Sleep Med 2011;7:459-65.

55. Luo J, Huang R, Zhong X, Xiao Y, Zhou J. STOPBang questionnaire is superior to Epworth sleepiness scales, Berlin questionnaire, and STOP questionnaire in screening obstructive sleep apnea hypopnea syndrome patients. Chin Med J 2014; 127:3065-70.

56. Proczko MA, Stepaniak PS, de Quelerij M, et al. STOP-Bang and the effect on patient outcome and 
length of hospital stay when patients are not using continuous positive airway pressure. J Anesth 2014; 28:891-7.

57. Chung F, Abdullah HR, Liao P. STOP-Bang Questionnaire: A practical approach to screen for obstructive sleep apnea. Chest. 2015 Sep 17. [Epub ahead of print].

58. Marcus CL, Brooks LJ, Draper KA, et al. Diagnosis and management of childhood obstructive sleep apnea syndrome. Pediatrics 2012;130:576-84.

59. Kadmon G, Chung SA, Shapiro CM. I'M SLEEPY: a short pediatric sleep apnea questionnaire. Int J Pediatr Otorhinolaryngol 2014;78:2116-20.

60. Raveendran R, Chung F. Perioperative consideration of obstructive sleep apnea in ambulatory surgery. Anesthesiol Clin 2014;32:321-8.

61. Kapoor M, Greenough G. Home sleep tests for obstructive sleep apnea (OSA). J Am Board Fam Med 2015;28:504-9.

62. White PF. The changing role of non-opioid analgesic techniques in the management of postoperative pain. Anesth Analg 2005;101(5 Suppl):S5-22.

63. Seet E, Chung F. Obstructive sleep apnea: preoperative assessment. Anesthesiol Clin 2010;28:199-215.
64. Porhomayon J, Leissner KB, El-Solh AA, Nader ND. Strategies in postoperative analgesia in the obese obstructive sleep apnea patient. Clin J Pain 2013;29:998-1005.

65. Patino M, Sadhasivam S, Mahmoud M. Obstructive sleep apnoea in children: perioperative considerations. Br J Anaesth 2013;111(Suppl 1):i83-95.

66. Subramanyam R, Varughese A, Willging JP, Sadhasivam S. Future of pediatric tonsillectomy and perioperative outcomes. Int J Pediatr Otorhinolaryngol 2013;77:194-9.

67. Strauss PZ. Perianesthesia implications of obstructive sleep apnea. Crit Care Nurs Q 2015;38: 97-108.

68. Auckley D, Cox R, Bolden N, Thornton JD. Attitudes regarding perioperative care of patients with OSA: a survey study of four specialties in the United States. Sleep Breath 2014;19:315-25.

69. Cordovani L, Chung F, Germain G, et al. Perioperative management of patients with obstructive sleep apnea: a survey of Canadian anesthesiologists. Can J Anesth/J Can Anesth 2015;63:16-23.

70. Seet E, Chung F. Management of sleep apnea in adults - functional algorithms for the perioperative period: Continuing Professional Development. Can J Anaesth 2010;57:849-64. 